\title{
Hyaluronan Reduces Surfactant Inhibition and Improves Rat Lung Function after Meconium Injury
}

\author{
KAREN W. LU, JON GOERKE, JOHN A. CLEMENTS, AND H. WILLIAM TAEUSCH \\ Departments of Pediatrics [K.W.L., J.A.C., H.W.T.] and Physiology [J.G.] and the Cardiovascular \\ Research Institute [J.G., J.A.C.], University of California, San Francisco, San Francisco, California 94110
}

ABSTRACT

\begin{abstract}
ABST
Hyaluronan (HA), an ionic polymer, is normally present in
the alveolar subphase and is known to decrease lung surfactant
inactivation caused by serum in vitro. In this study, we examined
whether HA can ameliorate the inactivating effects of meconium
in vitro and in vivo. Surface activities of various mixtures of
Survanta, HA, and meconium were measured using a modified
pulsating bubble surfactometer. With meconium, almost all sur-
face activity measures were improved by the addition of HA of
several molecular weights at a concentration of 0.25\%. Anesthe-
tized, paralyzed rats were maintained on positive-pressure ven-
tilation. After lung injury by instillation of meconium, they were
treated with Survanta, Survanta with HA, or control mixtures.
Serial measures of blood gases and peak inspiratory pressure
were recorded for the duration of the experiment. When the
Survanta plus HA group was compared with the Survanta alone
group, arterial oxygen tension averaged $117 \%$ higher, peak in-
\end{abstract}
Hyaluronan (HA) is an ionic polymer of alternating $\mathrm{N}$ acetylglucosamine and glucuronate units. It is one of the glycosaminoglycans that includes chondroitin, keratan, and heparan sulfates. Although HA has a simple chemical structure, it can assume a large number of conformations in aqueous solutions. These conformations allow HA to play many roles in biologic systems, such as being a space filler in the vitreous humor and serving as a viscoelastic substance in joints. In addition, HA interacts with cell surface receptors such as the receptor to HA-mediated motality RHAMM and CD44 (1-3). The biocompatibility of HA has led to many applications, including viscosurgery to allow the creation of space between tissues (4) and lubrication of arthritic joints.

Received October 15, 2004; accepted January 14, 2005

Correspondence: Karen W. Lu, M.D., San Francisco General Hospital, Department of Pediatrics, MS 6E, 1001 Potrero Avenue, San Francisco, CA 94110; e-mail: klu@sfghpeds.ucsf.edu.

Supported by National Heart, Lung, and Blood Institute Grants HL 66410 (Department of Pediatrics, University of California, San Francisco) and HL 24075 (Cardiovascular Research Institute, University of California, San Francisco).

DOI: 10.1203/01.PDR.0000169981.06266.3E spiratory pressure was $27 \%$ lower at the end of the experiment, and lung compliance also showed significant improvement. These results indicate that HA added to Survanta decreases inactivation caused by meconium in vitro and improves gas exchange and pulmonary mechanics of animals with meconiuminduced acute lung injury. (Pediatr Res 58: 206-210, 2005)

$\quad$ Abbreviations
HA, hyaluronan (hyaluronic acid)
PEG, polyethylene glycol
PIP, peak inspiratory pressure
PV, pressure-volume
SA, surface area
$\Delta \mathbf{A}_{\mathbf{1 0}}$, percentage decrease in surface area from the maximum
to reach a surface tension of $10 \mathrm{mN} / \mathrm{m}$

The role of HA in a variety of respiratory diseases has also been investigated by several groups. Cantor et al. (5-7) found that HA binds to elastic fibers, preventing elastolysis and limiting airspace enlargement in experimental models of emphysema induced by elastases. Forteza et al. (8) proposed that HA plays a major role in mucosal host defense by stimulating ciliary beating via the RHAMM. Because HA is secreted into the alveolar subphase by type II cells $(9,10)$, it has been suggested that it may interact with lung surfactant (11).

Our previous work has shown that adding HA to different lung surfactants improved the surface activity and decreased surfactant inactivation caused by serum (12). In this study, we investigated the effects of using HA Survanta mixtures in vitro and in vivo with meconium as the inactivating or injuryproducing substance.

\section{METHODS}

\footnotetext{
Materials. Three different molecular weights of HA were used. HA of 250 $\mathrm{kD}$ was purchased, and HA $660 \mathrm{kD}$ was a gift from GlycoMed Research, Inc. (Hastings-on-Hudson, NY). Molecular weights were determined by the manufacturer, extrapolating the viscosity to zero concentration, which gives estimates within $10 \%$ of direct measures. These HA preparations contain $<0.01 \%$
} 
protein and a ratio of hexuronic acid to hexosamine of 1:1 (characteristic of $\mathrm{HA}$ ) according to the manufacturer. HA of $1240 \mathrm{kD}$ was purchased from Sigma Chemical Co. (St. Louis, MO) with a protein concentration of $0.07 \%$. The amount of DNA in the HA used ranged from 0.9 to $1.7 \mathrm{ppm}$ determined by fluorescent assay (Molecular Probes, Eugene, OR). Endotoxin concentrations were $0.015-0.025 \mathrm{EU} / \mathrm{mg}$ HA measured by chromogenic Limulus amoebocyte assay (QLC-1000; BioWhittaker, Walkersville, MD). The three HA preparations were isolates from Streptococcus fermentation and were used as supplied.

Survanta was obtained from our neonatal intensive care unit. First-passed meconium was taken from urine-free diapers of normal term infants in our well-baby nursery.

In vitro study. Survanta was diluted in buffer $(0.9 \% \mathrm{NaCl}$ and $5 \mathrm{mM}$ of HEPES at a $\mathrm{pH}$ of 6.5) to a final concentration of $1.25 \mathrm{mg} / \mathrm{mL}$ phospholipid. Dry HA was added to Survanta to a final concentration of either 0.1 or $0.25 \%$ $(\mathrm{wt} / \mathrm{vol}$ ) and mixed by Vortex for $\sim 60 \mathrm{~s}$ at room temperature. Fresh meconium was added to the Survanta or Survanta HA mixture at a concentration of $2 \%$ (wt/vol) and mixed by Vortex for $40 \mathrm{~s}$ before testing within $30 \mathrm{~min}$.

Surface activity measurements were made with a modified pulsating bubble surfactometer (Electronetics, Buffalo, NY) using a technique that prevents wetting of the capillary tube (13). Pressure measurements were calibrated electronically according to the manufacturer's instructions and also checked with a water manometer. Surface tension measurements were calibrated using a variety of pure fluids with known surface tensions. Samples were maintained at $37^{\circ} \mathrm{C}$ throughout.

Quasi-equilibrium surface tension was defined as the surface tension $30 \mathrm{~s}$ after the formation of a static bubble with a radius of $0.40 \mathrm{~mm}$. This measure reflects the amount of surface-active material that had adsorbed to the airwater interface before cycling (inflation-deflation) of the bubble. Thereafter, the bubble was cycled at 20/min with the radius varying between 0.40 and 0.55 $\mathrm{mm}$. Minimum and maximum surface tensions were recorded at $60 \mathrm{~s}$ (10th cycle) and after $5 \mathrm{~min}$. The surface tension was calculated by the Laplace formula $p=2 \mathrm{ST} / \mathrm{r}$, where $\mathrm{ST}$ is the surface tension, $\mathrm{P}$ is the inflating pressure, and $\mathrm{r}$ is the radius of the bubble.

The percentage reduction in bubble surface area (SA) from its maximum value to that required for the surface tension to reach a value of $10 \mathrm{mN} / \mathrm{m}$ $\left(\Delta \mathrm{A}_{10}\right)$ was calculated after 5 min of bubble cycling. That is, $\Delta \mathrm{A}_{10}=[(\max$ $\mathrm{SA}-\mathrm{SA} @ 10 \mathrm{mN} / \mathrm{m}) / \mathrm{max} \mathrm{SA}] \times 100 \% . \Delta \mathrm{A}_{10}$ is an indicator of dynamic film compressibility over a range of the isotherm. Films with low compressibility produce a large decrease in surface tension with a relatively small decrease in SA. If the surface tension of the surfactant mixture did not reach $10 \mathrm{mN} / \mathrm{m}$, then the actual, although unmeasured $\Delta \mathrm{A}_{10}$ values had to have been $>47 \%$ because that is the difference in SA between the maximum and the minimum bubble areas in our pulsating bubble surfactometer. In these instances, we assigned a value of $47 \%$ for $\Delta \mathrm{A}_{10}$ for purposes of analysis, which leads to a conservative estimate of the level of significance. In total, six different indices of surface activity were recorded: minimum and maximum surface tensions at the 10th cycle and after $5 \mathrm{~min}, \Delta \mathrm{A}_{10}$, and quasi-equilibrium surface tension.

In vivo study. The animal protocol used was approved by the committee on animal research at the University of California, San Francisco. Male adult Sprague Dawley rats $(250-350 \mathrm{~g})$ were anesthetized by i.p. injection of pentobarbital at a dose of $100 \mathrm{mg} / \mathrm{kg}$. Pancuronium $(1 \mathrm{mg} / \mathrm{kg})$ was used for paralysis. The right carotid artery was catheterized for blood pressure measurements, sampling of blood gases, and drug or fluid infusion. $\mathrm{NaCl} 0.9 \%$ $\mathrm{wt} / \mathrm{vol}$ (saline) with 10 units $/ \mathrm{mL}$ heparin was used to flush the catheter. The trachea was cannulated, and the animals were supported on a computercontrolled ventilator (Flexivent; SCIREQ, Montreal, Canada) with initial settings of 50 breaths $/ \mathrm{min}$, tidal volume of $8 \mathrm{~mL} / \mathrm{kg}$ body weight, positive end-expiratory pressure of $4 \mathrm{~cm} \mathrm{H}_{2} \mathrm{O}$, fraction of inspired oxygen of 1.0, and flow of $0.5 \mathrm{~L} / \mathrm{min}$. Additional doses of pentobarbital at $7 \mathrm{mg} / \mathrm{kg}$ and pancuronium at $0.3 \mathrm{mg} / \mathrm{kg}$ were administered hourly into the carotid artery. Peak inspiratory pressures (PIPs) were recorded and the lung compliance values were recorded and calculated by the ventilator software throughout the experiment. Blood pressure values were measured using a Viggo-Spectromed transducer (Model P23XL; Gould, Valley View, $\mathrm{OH}$ ) attached to a recorder (Gould Windograf; Gould). Manometers were used to calibrate ventilator and blood transducers. Ventilation was adjusted to maintain $\mathrm{PCO}_{2}$ between 40 and $55 \mathrm{~mm} \mathrm{Hg}$ throughout the experiment, first by changing the frequency in the range of $50-70 / \mathrm{min}$ and then, if necessary, by adjusting the tidal volume to a maximum of $10.5 \mathrm{~mL} / \mathrm{kg}$.

Pooled fresh-frozen meconium from three to six infants was lyophilized. Dry meconium was mixed in sterile water by Vortex at a concentration of 30 $\mathrm{mg} / \mathrm{mL}$, then aspirated into a tuberculin syringe through a $27-\mathrm{G}$ needle. This mixture, at a dose of $4 \mathrm{~mL} / \mathrm{kg}$ body weight, was instilled into the trachea in $<10$ s while the anesthetized animal was in the supine position with the tracheal tube temporarily disconnected from the ventilator. Furosemide, at 10 $\mathrm{mg} / \mathrm{kg}$ body weight, was injected via the carotid artery 5 min after meconium injury to reduce fluid retention in the lungs (14).

Serial measures of blood gases, systemic arterial mean blood pressure, tidal volume, PIP, and lung compliance were recorded. Repeat doses of meconium $\left(1 \mathrm{~mL} / \mathrm{kg}\right.$ ) were administered as needed until the $\mathrm{Po}_{2}$ fell below $115 \mathrm{~mm} \mathrm{Hg}$.

Sixty minutes after the last dose of meconium, treatment was administered into the rat's lungs through the tracheostomy. Survanta was diluted to 12.5 $\mathrm{mg} / \mathrm{mL}$, then $0.25 \%$ (wt/vol) HA was added and mixed by Vortex for up to $60 \mathrm{~s}$ and maintained at $34^{\circ} \mathrm{C}$ for $1 \mathrm{~h}$ before instilling into the trachea. The $\mathrm{pH}$ of the Survanta HA mixture was 5.0. When Survanta alone was used, it was also heated to $34^{\circ} \mathrm{C}$ for $1 \mathrm{~h}$. The treatment dose was $4 \mathrm{~mL} / \mathrm{kg}$ body weight in all cases.

The 56 animals used were divided into seven groups. Groups 1-3 had no meconium injury. These animals received no treatment, treatment with HA of $250 \mathrm{kD}$ in saline, or treatment with saline only. Groups 4 and 5 were given meconium and were treated with saline or with HA in saline. Groups 6 and 7 were given meconium and then received $50 \mathrm{mg} / \mathrm{kg}$ Survanta, or Survanta 50 $\mathrm{mg} / \mathrm{kg}$ with HA of $250 \mathrm{kD}$, respectively. The concentration of HA both in saline and in Survanta was $0.25 \%$ (wt/vol). The choice of $50 \mathrm{mg} / \mathrm{kg}$ Survanta was based on our previous studies of meconium lung injury in which we found that the addition of polyethylene glycol (PEG) to $50 \mathrm{mg} / \mathrm{kg}$ Survanta significantly improved measures of gas exchange and lung mechanics when compared with $50 \mathrm{mg} / \mathrm{kg}$ Survanta alone (15). We chose to use the same protocol with respect to injury model, surfactant, and dose as in the previous studies. The molecular weight and concentration of HA for the in vivo study were selected on the basis of pilot studies. The molecular weight of HA used (250 $\mathrm{kD})$ is close to the molecular weight $(220 \mathrm{kD})$ of HA secreted by the alveolar cells $(11,16)$ and has less apparent viscosity compared with higher molecular weight HA.

Three hours after treatment, additional pentobarbital $(100 \mathrm{mg} / \mathrm{kg})$ was given through the arterial catheter, and the lungs were degassed by tracheal clamping while the heart was still beating. The abdomen and the diaphragm were opened, and the vena cava was cut. Post mortem quasi-static deflation pressure-volume (PV) curves were made in the open-chested animals by first inflating the lungs to a pressure of $35 \mathrm{~cm} \mathrm{H}_{2} \mathrm{O}$. After a period of stabilization ( $45 \mathrm{~s}$, or when $<0.1 \mathrm{~mL}$ of air entered in $10 \mathrm{~s}$ ), the inflating volume was taken as the total lung capacity. Pressure was reduced in steps of $5 \mathrm{~cm} \mathrm{H}_{2} \mathrm{O}$ with at least $10 \mathrm{~s}$ of stabilization at each step, and the corresponding volumes were recorded. The volume was corrected for compression in the dead space of the apparatus. The lungs then were removed, blotted, and weighed. A whole midsagittal slice of the left lung was taken for histologic scoring, and the remaining part of the lungs were weighed wet and then again after drying at $70^{\circ} \mathrm{C}$ for $24 \mathrm{~h}$

The left lung segment was placed in $4 \%$ formalin, embedded in paraffin, and stained with hematoxylin and eosin. Because the sections were coded, the specimens were graded without knowledge of the experimental groupings. These sections were examined by light microscopy with particular reference to meconium in the airways, intra-alveolar edema, leukocytes, hemorrhage, alveolar debris, atelectasis, overexpansion of alveoli, and hyaline membranes. Each of these features was scored $0-3$ by two different observers $(0=$ absent, $1=$ mild, $2=$ moderate, and $3=$ prominent $)$.

Analysis. For the in vitro data and the in vivo lung weight and histology data, the measurements were analyzed by one-way ANOVA using SigmaStat software (SPSS Science, Chicago, IL). Comparisons between pairs of groups were done using either the Tukey test or the Kruskal-Wallis test when necessary to correct for multiple comparisons. For the in vivo data, serial measurements were analyzed by two-way repeated ANOVA. A $p \leq 0.05$ was considered statistically significant.

\section{RESULTS}

In Vitro Study. Various mixtures were studied: Survanta with no HA in the presence or absence of meconium, and Survanta with HA of three molecular weights and two concentrations $(250,660$, and $1240 \mathrm{kD}$ at 0.1 or $0.25 \% \mathrm{wt} / \mathrm{vol})$ with or without meconium for a total of 14 surfactant mixtures. For each mixture, the previously mentioned six measures of surface activity were recorded. In general, surface activity of Survanta was clearly improved by the addition of HA both in the absence and in the presence of meconium.

$\boldsymbol{H A}$ at 0.1\%. When HA was added to Survanta without meconium, significant improvements $(p<0.05)$ were found for the minimum surface tension after 5 min for HA of 250 and 
$660 \mathrm{kD}$ and $\Delta \mathrm{A}_{10}$ for HA of $250 \mathrm{kD}$ (data not shown). There were no significant differences in either quasi-equilibrium or maximum surface tensions. When meconium was present, minimum surface tensions (10th cycle and $5 \mathrm{~min}$ ) and $\Delta \mathrm{A}_{10}$ showed significant improvement with 1240-kD HA $(p<0.05$; Fig. $1 A$ ), but there was little effect on the quasi-equilibrium surface tension.

$\boldsymbol{H A}$ at $\mathbf{0 . 2 5 \%}$. With the addition of HA $0.25 \%$ to Survanta without meconium, minimum surface tensions (10th cycle and after $5 \mathrm{~min}$ ) and $\Delta \mathrm{A}_{10}$ (Fig. $1 B$ ) were significantly improved for all three molecular weights of HA. Little effect on quasiequilibrium or maximum surface tensions was noted when HA was present with Survanta. However, when meconium was present, quasi-equilibrium surface tension, minimum surface tensions (10th cycle and after $5 \mathrm{~min}$ ), and $\Delta \mathrm{A}_{10}$ were significantly improved (Fig. 1). Quasi-equilibrium surface tension was $32 \pm 2 \mathrm{mN} / \mathrm{m}$ with Survanta alone and $25 \pm 1,29 \pm 2$, and $25 \pm 1$ when HA of 1240,660 , and $250 \mathrm{kD}$ was added to Survanta ( $p<0.05$ in all cases). Maximum surface tensions both at the 10th cycle and after 5 min were not different when HA of $250 \mathrm{kD}$ was added to Survanta, but they were significantly higher with $1240-$ or $660-\mathrm{kD}$ HA (data not shown).

Molecular weight. Overall, 1240-kD HA improved measures of surface activity to a greater degree than the two HAs of lower molecular weight. HA of $1240 \mathrm{kD}$ improved the minimum surface tension after $5 \mathrm{~min}$ of cycling and $\Delta \mathrm{A}_{10}$ when $0.1 \%$ HA was added to Survanta in the presence of meconium, but HA of 660 or $250 \mathrm{kD}$ did not do so. In general, molecular weight effects were more evident at $0.1 \%$ HA concentration than at $0.25 \%$ when meconium was present (Fig. 1).

In Vivo Study. Fifty of the 56 animals survived for the duration of the experiment. The six deaths were limited to those with lung injury treated with saline or saline plus HA. Table 1 lists the blood pressure, $\mathrm{Po}_{2}, \mathrm{PCO}_{2}$, PIP, lung compliance, $\mathrm{pH}$, and base deficit for these two injury control groups and for the Survanta or Survanta with HA groups before and $3 \mathrm{~h}$ after treatment. Mean arterial blood pressure and $\mathrm{pH}$ were significantly lower for the group that was treated with Survanta compared with the Survanta HA group (two-way ANOVA for repeated measures: $p<0.05$ ). There were no significant differences between groups before treatment.

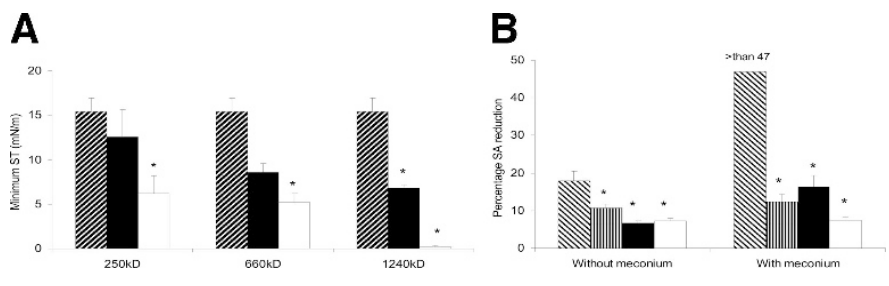

Figure 1. (A) In vitro studies. Minimum surface tension after 5 min of cycling is shown for Survanta with meconium inactivation with or without HA of 250, 660 , or $1240 \mathrm{kD}$ at either 0.1 or $0.25 \%$ (wt/vol) concentration $(n=5)$. $\mathbb{Q}$, Survanta without HA; $\mathbf{\square}$, Survanta with $0.1 \%$ HA; $\square$, surfactant with HA $0.25 \% ; * p<0.05$ for comparisons of surfactant with or without HA (by ANOVA corrected for multiple comparisons). (B) $\Delta \mathrm{A}_{10}$ is shown for Survanta with or without meconium and no HA or HA of 250,660 , or $1240 \mathrm{kD}(0.25 \%$; $n=5$ ). $\mathbb{\mathbb { Q }}$, Survanta without HA; 四, Survanta with HA $250 \mathrm{kD}$; $\mathbf{\square}$, Survanta with HA of $660 \mathrm{kD} ; \square$, Survanta with HA of $1240 \mathrm{kD}$; $* p<0.05$ for comparisons of Survanta with or without HA (by ANOVA corrected for multiple comparisons).
Three control groups received no meconium injury and were given saline, HA, or no treatment. There was no significant difference among them for blood pressure, $\mathrm{pH}$, base deficit, oxygenation, or PIP (Figs. $2 A$ and $3 A$ ). Lung compliance was similar among these groups. Analyses of PV curves showed no differences between the HA and saline groups, but both were significantly different when compared with the no injury and no treatment group (two-way ANOVA for repeated measures: $p<0.05$; Fig. 4A). Mean $\mathrm{Po}_{2}$ for noninjured groups remained near $500 \mathrm{~mm} \mathrm{Hg}$ throughout the experiment. PIP and lung compliance did not differ significantly between the no treatment group and either the HA or the saline group.

Two groups received meconium injury and were treated with either saline or HA. There were no significant differences between them with regard to oxygenation, PIP, lung compliance, or PV curves. There were three deaths after treatment in the saline group and also in the HA group. Mean $\mathrm{Po}_{2}$ was near $100 \mathrm{~mm} \mathrm{Hg}$ throughout the experiment after injury (Fig. 2A). Average PIP was 2-2.5 times higher after injury compared with values before (Fig. 3A). PV curves for these two groups were similar. Three animals in each of these two groups survived for the duration of the experiment, and although the HA group had greater base deficit, lower $\mathrm{pH}$, and lower blood pressure, these differences were not significant when analyzed by two-way ANOVA or $t$ test (Table 1).

Figures $2 B$ and $3 B$ compare results for groups that were treated with either Survanta alone or Survanta with HA and show significant benefit for the Survanta HA group for serial $\mathrm{Po}_{2}$ and PIP. The Survanta HA group also showed better lung compliance when compared with the Survanta alone group ( $p$ $<0.05$; Table 1). PV curves were not significantly different when two-way ANOVA repeated measures was used to analyze the differences between the Survanta and Survanta with HA groups (Fig. 4B). However, the Survanta with HA group was not significantly different from the no injury/no treatment group, whereas the PV curve for the group that was treated with Survanta alone was significantly shifted from the no injury/no treatment group.

The lung weights and the ratio of dry/wet lung weights were not significantly different when one-way ANOVA was used to compare Survanta and Survanta with HA groups. The lung weights as a percentage of body weight seemed lower in the Survanta with HA group $(0.8 \pm 0.1)$ compared with the Survanta alone group $(1.1 \pm 0.1)$, but this difference was not significant.

Histologic scores revealed no significant differences among groups with lung injury for alveolar edema, leukocytes, hemorrhage, alveolar debris, or atelectasis. However, the Survanta alone group showed significantly higher levels of alveolar overexpansion compared with the Survanta with HA group ( $p$ $<0.05$; Fig. 5).

\section{DISCUSSION}

Addition of HA to Survanta improves surface activity in the presence or absence of meconium. The size of the effect depends on the concentration and molecular weight of HA. At the higher concentration, all molecular weights of HA were 
Table 1. Average values for animals in injury groups before treatment, and three hours after treatment ( \pm SEM).

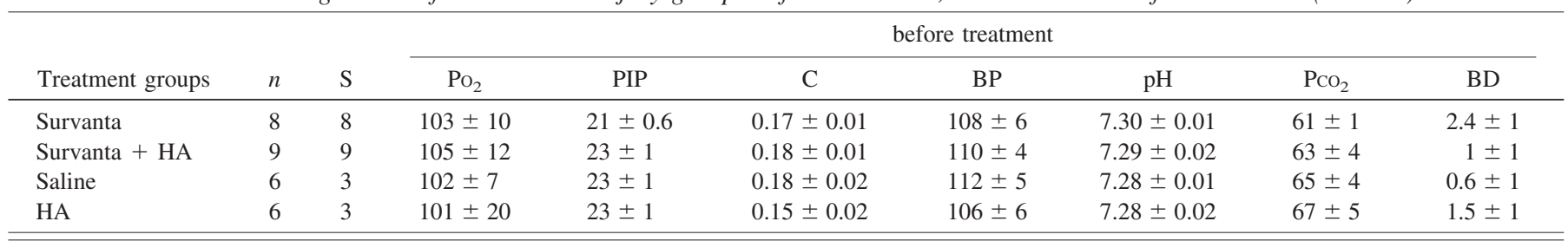

\begin{tabular}{|c|c|c|c|c|c|c|c|c|c|}
\hline \multirow[b]{2}{*}{ Treatment groups } & \multirow[b]{2}{*}{$n$} & \multirow[b]{2}{*}{$\mathrm{S}$} & \multicolumn{7}{|c|}{$3 \mathrm{~h}$ after treatment } \\
\hline & & & $\mathrm{PO}_{2}$ & PIP & $\mathrm{C}$ & $\mathrm{BP}$ & $\mathrm{pH}$ & $\mathrm{PCO}_{2}$ & $\mathrm{BD}$ \\
\hline Survanta & 8 & 8 & $195 \pm 49$ & $23 \pm 2$ & $0.18 \pm 0.02$ & $71 \pm 12$ & $7.30 \pm 0.02$ & $49 \pm 5.3$ & $-2.7 \pm 3$ \\
\hline Saline & 6 & 3 & $177 \pm 53$ & $22 \pm 1$ & $0.2 \pm 0.1$ & $116 \pm 6$ & $7.24 \pm 0.04$ & $54 \pm 3$ & $-0.5 \pm 3$ \\
\hline HA & 6 & 3 & $123 \pm 25$ & $29 \pm 2$ & $0.11 \pm 0.3$ & $46 \pm 22$ & $7.03 \pm 0.1$ & $55 \pm 12$ & $-17 \pm 6$ \\
\hline
\end{tabular}

Survanta $=$ Survanta $50 \mathrm{mg} / \mathrm{kg}$; Survanta $+\mathrm{HA}=$ Survanta $50 \mathrm{mg} / \mathrm{kg}+\mathrm{HA} 250 \mathrm{kD} 0.25 \%(\mathrm{wt} / \mathrm{vol}) ; n=$ number of animals in the group; $\mathrm{S}=$ number of animals surviving 3 hours; $\mathrm{Po}_{2}$ in $\mathrm{mm} \mathrm{Hg}$; $\mathrm{PIP}=$ peak inspiratory pressure in $\mathrm{cm} \mathrm{H}_{2} \mathrm{O} ; \mathrm{C}=$ lung compliance in $\mathrm{mL} / \mathrm{cm} \mathrm{H}_{2} \mathrm{O}$; $\mathrm{BP}=$ mean systemic arterial blood pressure in $\mathrm{mm} \mathrm{Hg} ; \mathrm{PCO}_{2}$ in $\mathrm{mm} \mathrm{Hg} ; \mathrm{BD}=$ base deficit in $\mathrm{mEq} / \mathrm{L}$.

$* p<0.05$ when comparing four sequential values for Survanta + HA vs. Survanta (two-way ANOVA for repeated measures).

effective, whereas at the lower concentration, only the highest molecular weight HA gave beneficial results. In animal experiments, HA added to Survanta improved measures of gas exchange and lung mechanics.

In normal alveolar fluid from rats, HA has an estimated concentration of $\sim 4 \mu \mathrm{g} / \mathrm{mL}$ and a molecular weight of $\sim 220 \mathrm{kD}$ (11). This may be an underestimation because of the inefficiency of removal of protein-bound HA and because of diffi-
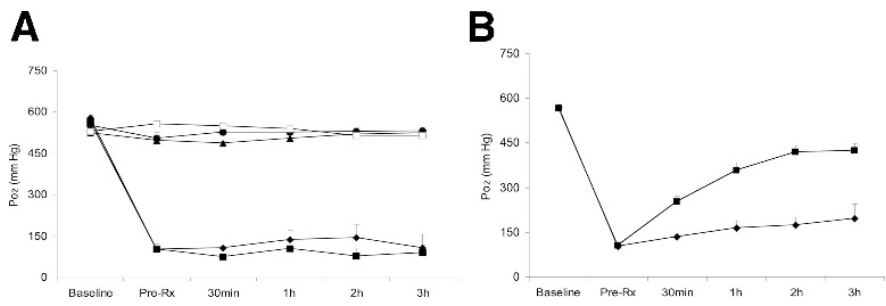

Figure 2. Animal studies. Serial measures of $\mathrm{Po}_{2}$ are shown for the five control groups $(A)$ and for the two treatment groups $(B)$. In $A, \diamond$, mean values for meconium injury with saline treatment; $\boldsymbol{\square}$, meconium injury with HA treatment; $\bullet$, HA and no meconium injury; $\boldsymbol{\Lambda}$, saline and no meconium injury; $\square$, no meconium injury and no treatment. In $B, \diamond$, values for animals that had meconium injury and were treated with Survanta alone; $\mathbf{\square}$, animals that had meconium injury and were treated with Survanta plus HA of $250 \mathrm{kD}$. There is a significant difference between these two groups (with and without HA; $p<$ $0.001)$.
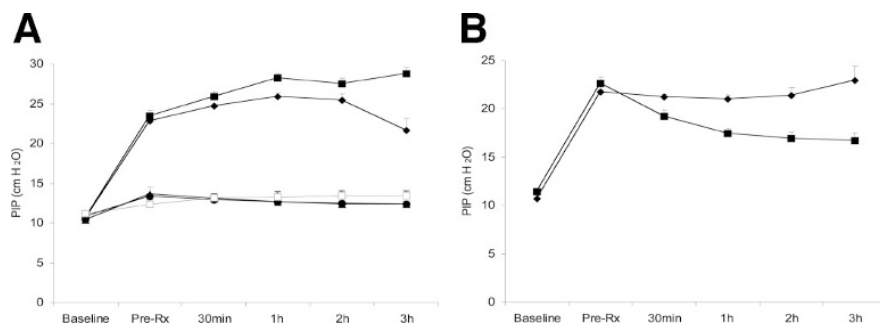

Figure 3. Serial measures of peak inspiratory airway pressures are shown for five control groups $(A)$ and two treatment groups $(B)$. The symbols used for the groups are the same as in Fig. 2. The group that was treated with Survanta alone is significantly different from the group that was treated with Survanta plus HA of $250 \mathrm{kD}$ when analyzed by two-way ANOVA $(p<0.001)$. culties in ascertaining subphase volumes (17). For the in vivo experiments, we used HA of similar molecular weight but at higher concentration.

Various properties of HA may account for the alterations that it produces in surface activity of surfactant. HA is known to bind many times its own weight of water $(11,18)$. By binding water molecules, HA may increase the concentration of other large molecules in the nonbound water, including surfactant, and thus mitigate inactivation. Ghosh et al. $(19,20)$ observed that phospholipids can interact with HA to form complexes. The formation of phospholipid HA aggregates may stabilize surfactant phospholipids at the air-water interface and/or increase surface adsorption of subphase lipids. HA in addition to

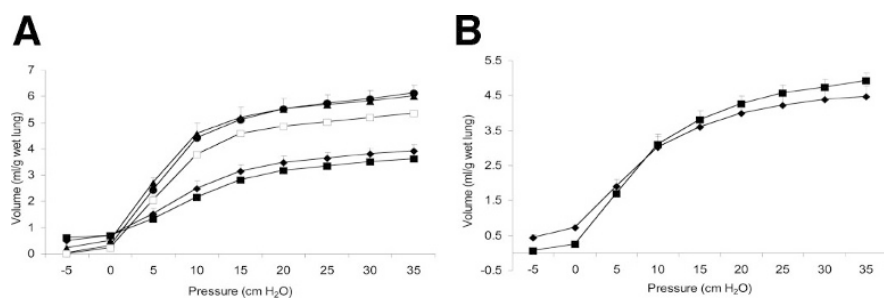

Figure 4. Average deflation PV curve for the five control groups $(A)$ and two treatment groups $(B)$. Wet lung weight was calculated as $0.8 \%$ of body weight. The symbols for the different groups are the same as in Figs. 2 and 3.
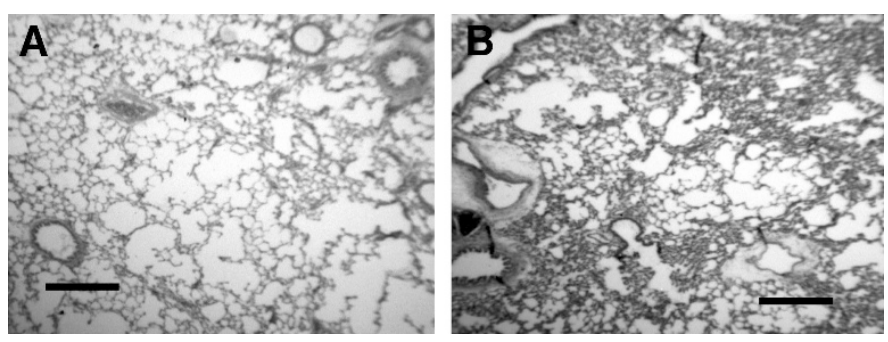

Figure 5. Low-power photomicrographs of the lungs stained with hematoxylin and eosin from two animals. (Left) The lung from an animal that had lung injury treated with Survanta alone. (Right) The lung from an animal that was treated with Survanta and HA of $250 \mathrm{kD}$. Note that alveolar overexpansion is significantly increased in the animal that was treated with Survanta alone $(p<$ 0.05). Bars $=500 \mu \mathrm{m}$. 
its hydrophilic properties has hydrophobic regions created by its molecular shape that could potentially serve as interaction sites for the hydrophobic surfactant proteins B and C (11).

HA molecules can interact with each other and form various aggregates such as three-dimensional networks or isolated clumps $(21,22)$. The properties of these forms depend on the concentration and molecular weight of $\mathrm{HA}$ in the aqueous solution. Heatley et al. (23) suggested that a high concentration of higher molecular weight $\mathrm{HA}(>1.0 \mathrm{mg} / \mathrm{mL})$ produces random coils or chains that become entangled to form extended three-dimensional structures, and chain-chain overlap occurs. When the HA concentration is $<0.1 \%$, the HA molecules do not overlap (24). The three-dimensional macromolecular mesh of HA may serve to separate inactivating substances from surfactant by acting as a size-discriminating filter (25). The shape, size, and extent of the network depends also on the molecular weight of the HA, with HA of $<\sim 340 \mathrm{kD}$ forming patchwork islands rather than an integrated mesh as does HA $>1000 \mathrm{kD}$ (26).

Our previous studies and those of others found that some nonionic polymers such as PEG and dextran improve surface activity and reduce surfactant inactivation in vitro and in vivo $(15,27-33)$ presumably as a result of depletion forces enhancing surfactant subphase to surface adsorption $(30,34)$. Does HA affect surfactants in a similar way? HA, PEG, and dextran share the property of binding water, but HA has much higher binding capacity per unit weight, and it is a charged polymer. The finding that HA is effective with several surfactants (12) is in contrast to results with nonionic polymers, in which dextran was found to be significantly more effective with Curosurf than was PEG, and PEG was more effective with Survanta than was dextran (35). These combined findings suggest that ionic and nonionic polymers may affect surfactants by different mechanisms.

The results of this study indicate that HA, a substance that naturally occurs in alveolar fluid, may have beneficial effects on surfactant under normal and abnormal conditions. The concentration and molecular weight of HA to be used needs further study to maximize the beneficial effects. The present findings provide evidence that the addition of ionic polymers such as HA to surfactant could improve pulmonary function in a variety of acute lung injuries.

Acknowledgments. We thank Cynthia Brown and Cheryl Chapin for measuring lipopolysaccharide and DNA concentrations in the HA preparations.

\section{REFERENCES}

1. Underhill CB, Green SJ, Comoglio PM, Tarone G 1987 The hyaluronate receptor is identical to a glycoprotein of $\mathrm{Mr} 85,000$ (gp85) as shown by a monoclonal antibody that interferes with binding activity. J Biol Chem 262:13142-13146

2. Turley EA, Austen L, Vandeligt K, Clary C 1991 Hyaluronan and a cell-associated hyaluronan binding protein regulate the locomotion of ras-transformed cells. J Cell Biol 112:1041-1047

3. Turley EA, Noble PW, Bourguignon LY 2002 Signaling properties of hyaluronan receptors. J Biol Chem 277:4589-4592

4. Balazs EA, Denlinger JL 1989 Clinical uses of hyaluronan. Ciba Found Symp $143: 265-275$
5. Cantor JO, Cerreta JM, Armand G, Turino GM 1997 Further investigation of the use of intratracheally administered hyaluronic acid to ameliorate elastase-induced emphysema. Exp Lung Res 23:229-244

6. Cantor JO, Cerreta JM, Armand G, Turino GM 1998 Aerosolized hyaluronic acid decreases alveolar injury induced by human neutrophil elastase. Proc Soc Exp Biol Med 217:471-475

7. Cantor JO, Shteyngart B, Cerreta JM, Liu M, Armand G, Turino GM 2000 The effect of hyaluronan on elastic fiber injury in vitro and elastase-induced airspace enlargement in vivo. Proc Soc Exp Biol Med 225:65-71

8. Forteza R, Lieb T, Aoki T, Savani RC, Conner GE, Salathe M 2001 Hyaluronan serves a novel role in airway mucosal host defense. FASEB J 15:2179-2186

9. Sahu SC, Tanswell AK, Lynn WS 1980 Isolation and characterization of glycosaminoglycans secreted by human foetal lung type II pneumocytes in culture. J Cell Sci 42:183-188

10. Skinner SJ, Post M, Torday JS, Stiles AD, Smith BT 1987 Characterization of proteoglycans synthesized by fetal rat lung type II pneumonocytes in vitro and the effects of cortisol. Exp Lung Res 12:253-264

11. Bray BA 2001 The role of hyaluronan in the pulmonary alveolus. J Theor Biol 210:121-130

12. Lu KW, Goerke J, Clements JA, Taeusch HW 2005 Hyaluronan decreases surfactant inactivation in vitro. Pediatr Res 57:237-241

13. Putz G, Goerke J, Taeusch HW, Clements J 1994 Comparison of captive and modified pulsating bubble surfactometers with the use of lung surfactants. J Appl Physiol 76:1425-1431

14. Sun B, Curstedt T, Robertson B 1996 Exogenous surfactant improves ventilation efficiency and alveolar expansion in rats with meconium aspiration. Am J Respir Crit Care Med 154:764-770

15. Lu KW, Taeusch HW, Robertson B, Goerke J, Clements JA 2000 Polymer-surfactant treatment of meconium-induced acute lung injury. Am J Respir Crit Care Med 162:623-628

16. Nettelbladt O, Tengblad A, Hallgren R 1989 Lung accumulation of hyaluronan parallels pulmonary edema in experimental alveolitis. Am J Physiol 257:L379-L384

17. Bastacky J, Lee CY, Goerke J, Koushafar H, Yager D, Kenaga L, Speed TP, Chen Y, Clements JA 1995 Alveolar lining layer is thin and continuous: low-temperature scanning electron microscopy of rat lung. J Appl Physiol 79:1615-1628

18. Ogston AG, Stanier JE 1951 The dimensions of the particle of hyaluronic acid complex in synovial fluid. Biochem J 49:585-590

19. Ghosh P, Hutadilok N, Adam N, Lentini A 1994 Interactions of hyaluronan (hyaluronic acid) with phospholipids as determined by gel permeation chromatography, multi-angle laser-light-scattering photometry and 1H-NMR spectroscopy. Int J Biol Macromol 16:237-244

20. Pasquali-Ronchetti I, Quaglino D, Mori G, Bacchelli B, Ghosh P 1997 Hyaluronanphospholipid interactions. J Struct Biol 120:1-10

21. Scott JE 1989 Secondary structures in hyaluronan solutions: chemical and biological implications. Ciba Found Symp 143:6-15

22. Jacoboni I, Valdre U, Mori G, Quaglino D Jr, Pasquali-Ronchetti I 1999 Hyaluronic acid by atomic force microscopy. J Struct Biol 126:52-58

23. Heatley F, Scott JE 1988 A water molecule participates in the secondary structure of hyaluronan. Biochem J 254:489-493

24. Hascall VC, Laurent TC 2004 Hyaluronan: structure and physical properties. Available at: www.glycoforum.gr.jp/science/hyaluronan/HA01/HA01E.html. Accessed July 15,2004

25. Laurent TC 1970 Structure of hyaluronic acid. In: Balazs EA (ed) Chemistry and Molecular Biology of the Intercellular Matrix. Academic Press, London, pp 703-732

26. Yanaki T, Yamaguchi T 1990 Temporary network formation of hyaluronate under a physiological condition. 1. Molecular-weight dependence. Biopolymers 30:415-425

27. William Taeusch H, Lu KW, Goerke J, Clements JA 1999 Nonionic polymers reverse inactivation of surfactant by meconium and other substances. Am J Respir Crit Care Med 159:1391-1395

28. Kobayashi T, Ohta K, Tashiro K, Nishizuka K, Chen WM, Ohmura S, Yamamoto K 1999 Dextran restores albumin-inhibited surface activity of pulmonary surfactant extract. J Appl Physiol 86:1178-1184

29. Lu JJ, Cheung WW, Yu LM, Policova Z, Li D, Hair ML, Neumann AW 2002 The effect of dextran to restore the activity of pulmonary surfactant inhibited by albumin. Respir Physiol Neurobiol 130:169-179

30. Yu LM, Lu JJ, Chiu IW, Leung KS, Chan YW, Zhang L, Policova Z, Hair ML, Neumann AW 2004 Poly(ethylene glycol) enhances the surface activity of a pulmonary surfactant. Colloids Surf B Biointerfaces 36:167-176

31. Lu KW, Taeusch HW, Robertson B, Goerke J, Clements JA 2001 Polyethylene glycol/surfactant mixtures improve lung function after $\mathrm{HCl}$ and endotoxin lung injuries. Am J Rev Respir Crit Care Med 164:1531-1536

32. Tashiro K, Cui XG, Kobayashi T, Curstedt T, Robertson B 2003 Modified protocols for surfactant therapy in experimental meconium aspiration syndrome. Biol Neonate $83: 49-56$

33. Cui XG, Tashiro K, Matsumoto H, Tsubokawa Y, Kobayashi T 2003 Aerosolized surfactant and dextran for experimental acute respiratory distress syndrome caused by acidified milk in rats. Acta Anaesthesiol Scand 47:853-860

34. Kuhl T, Guo Y, Aldefer JL, Berman AD, Leckband D, Israelachvili J, Hui SW 1996 Direct measurement of polyethylene glycol induced depletion attraction between lipid bilayers. Langmuir 12:3003-3014

35. Lu KW, Taeusch HW2001 Polymer effects differ with Survanta, Curosurf and Infasurf. J Investig Med 49:28A 